Article

\title{
Enhanced Inhibition of Drug-Resistant Escherichia coli by Tetracycline Hydrochloride-Loaded Multipore Mesoporous Silica Nanoparticles
}

\author{
Zhumiao Ye, Shaochen Wang, Yuelong $X u$, Jianhao Zhang and Wenjing Yan * \\ National Center of Meat Quality \& Safety Control, College of Food Science and Technology, \\ Nanjing Agricultural University, Nanjing 210095, China; 2020108054@stu.njau.edu.cn (Z.Y.); \\ wsc@njau.edu.cn (S.W.); 2019108056@njau.edu.cn (Y.X.); nau_zjh@njau.edu.cn (J.Z.) \\ * Correspondence: ywj1103@njau.edu.cn; Tel.: +86-01-589-589-3834
}

Citation: Ye, Z.; Wang, S.; Xu, Y.; Zhang, J.; Yan, W. Enhanced Inhibition of Drug-Resistant Escherichia coli by Tetracycline Hydrochloride-Loaded Multipore Mesoporous Silica Nanoparticles. Molecules 2022, 27, 1218. https:// doi.org/10.3390/molecules27041218

Academic Editor: Abel Santos

Received: 17 January 2022

Accepted: 4 February 2022

Published: 11 February 2022

Publisher's Note: MDPI stays neutral with regard to jurisdictional claims in published maps and institutional affiliations.

Copyright: (C) 2022 by the authors. Licensee MDPI, Basel, Switzerland. This article is an open access article distributed under the terms and conditions of the Creative Commons Attribution (CC BY) license (https:// creativecommons.org/licenses/by/ $4.0 /)$.

\begin{abstract}
Drug-resistant bacterial infections exhibit a major threat to public health. Thus, exploring a novel antibacterial with efficient inhibition is urgently needed. Herein, this paper describes three types of MSNs (MSNs-FC2-R1, MSNs-FC2-R0.75, MSNs-FC2-R0.5) with controllable pore size $(4-6 \mathrm{~nm})$ and particle size $(30-90 \mathrm{~nm})$ that were successfully prepared. The MSNs were loaded with tetracycline hydrochloride (TCH) for effective inhibition of Escherichia coli (ATCC25922) and TCH-resistant Escherichia coli (MQ776). Results showed that the loading capacity of TCH in three types of MSNs was as high as over $500 \mathrm{mg} / \mathrm{g}$, and the cumulative release was less than $33 \%$ in $60 \mathrm{~h}$. The inhibitory rate of MSNs-FC2-R0.5 loaded with TCH against E. coli and drug-resistant E. coli reached $99.9 \%$ and $92.9 \%$ at the concentration of MIC, respectively, compared with the other two types of MSNs or free TCH. Modified MSNs in our study showed a great application for long-term bacterial growth inhibition.
\end{abstract}

Keywords: mesoporous silica nanoparticles; tetracycline hydrochloride; drug-resistant Escherichia coli; long-term antibacterial activity

\section{Introduction}

The number of drug-resistant bacteria has increased exponentially over the past few years due to the abuse of antibiotics in agriculture and human health services, which poses big challenges to disease prevention and control [1]. Humans could face a post-antibiotic age because of the lost efficacy in existing antibiotics, and by then, even the simplest cold could be fatal [2]. Therefore, developing new bactericides that can combat bacterial and drug-resistant bacteria with long-term efficiency is a great emergency.

Mesoporous silica nanoparticles (MSNs) are inorganic silica nanocarrier materials with tunable pore sizes from 2 to $50 \mathrm{~nm}$. Because of the unprecedented advantages of high stability, large surface area, great biocompatibility, and versatile functionalization, MSNs have attracted more and more attention in the field of biomedicine, especially in the drug delivery system [3,4]. The excellent mesoporous structure with an adjustable pore size facilitates effective drug loading and controlled release. Moreover, the easily modified surface of MSNs enhances the drug's therapeutic efficacy and reduces toxicity, which has been approved by the US Food and Drug Administration. The prominent characteristics of MSNs provide a great opportunity for antibacterial therapy.

MSNs, functionalized with antimicrobial molecules (antibiotics, amino acids, enzymes, etc.) on the external surface or loaded with antimicrobial molecules, presented a marked inhibition of common pathogenic bacteria compared with free antibacterial molecules [5]. Tetracycline hydrochloride (TCH) is a common broad-spectrum antibiotic used for the inhibition of gram-positive and gram-negative bacteria, and its inhibitory effect on gram-positive bacteria is better than gram-negative bacteria, so the resistance 
of gram-negative bacteria to tetracycline hydrochloride is very serious [6]. Koneru et al. demonstrated that mobile crystalline material 41 (MCM-41) loaded with TCH showed a greater inhibition on E. coli after $4 \mathrm{~h}$ compared with free TCH. However, the loading efficiency and the antibacterial activity using MCM-41 were too low to be applied in practice [7].

Herein, dendritic MSNs with three different pore sizes (4-6 nm) were synthesized by adjusting the ratio of FC2 (sodium trifluoroacetate) and CTAB (Cetyltrimethylammonium bromide) [8]. The MSNs werWe loaded with TCH for the inhibition of common Escherichia coli (ATCC25922) and drug-resistant Escherichia coli (MQ776) [9] in vitro. The physicochemical characterization of MSNs including morphology, particle size, zeta potential, pore diameter and loading and release capacity was assessed. The antibacterial activity of MSNs loaded with TCH against Escherichia coli and drug-resistant Escherichia coli was demonstrated. TEM images and the leakage amount of protein and nucleic acid were used to reveal antimicrobial mechanisms of MSNs.

\section{Results and Discussion}

\subsection{Characterization of MSNs}

Figure 1A-C shows the morphology of MSNs-FC2-R1, MSNs-FC2-R0.75, and MSNsFC2-R0.5 observed by high-resolution TEM. It was noted that three types of MSNs were spherical silica nanoparticles with large-pore dendritic structures. The average particle sizes measured by TEM were 90,50, and $30 \mathrm{~nm}$, respectively, for three types of MSNs. The hydrodynamic diameters of MSNs-FC2-R1, MSNs-FC2-R0.75, and MSNs-FC2-R0.5 measured by dynamic light scattering (DLS) were 330, 192, and $180 \mathrm{~nm}$, respectively (Figure 1D), which is larger than that of TEM due to the strong surface hydration of silica [10].
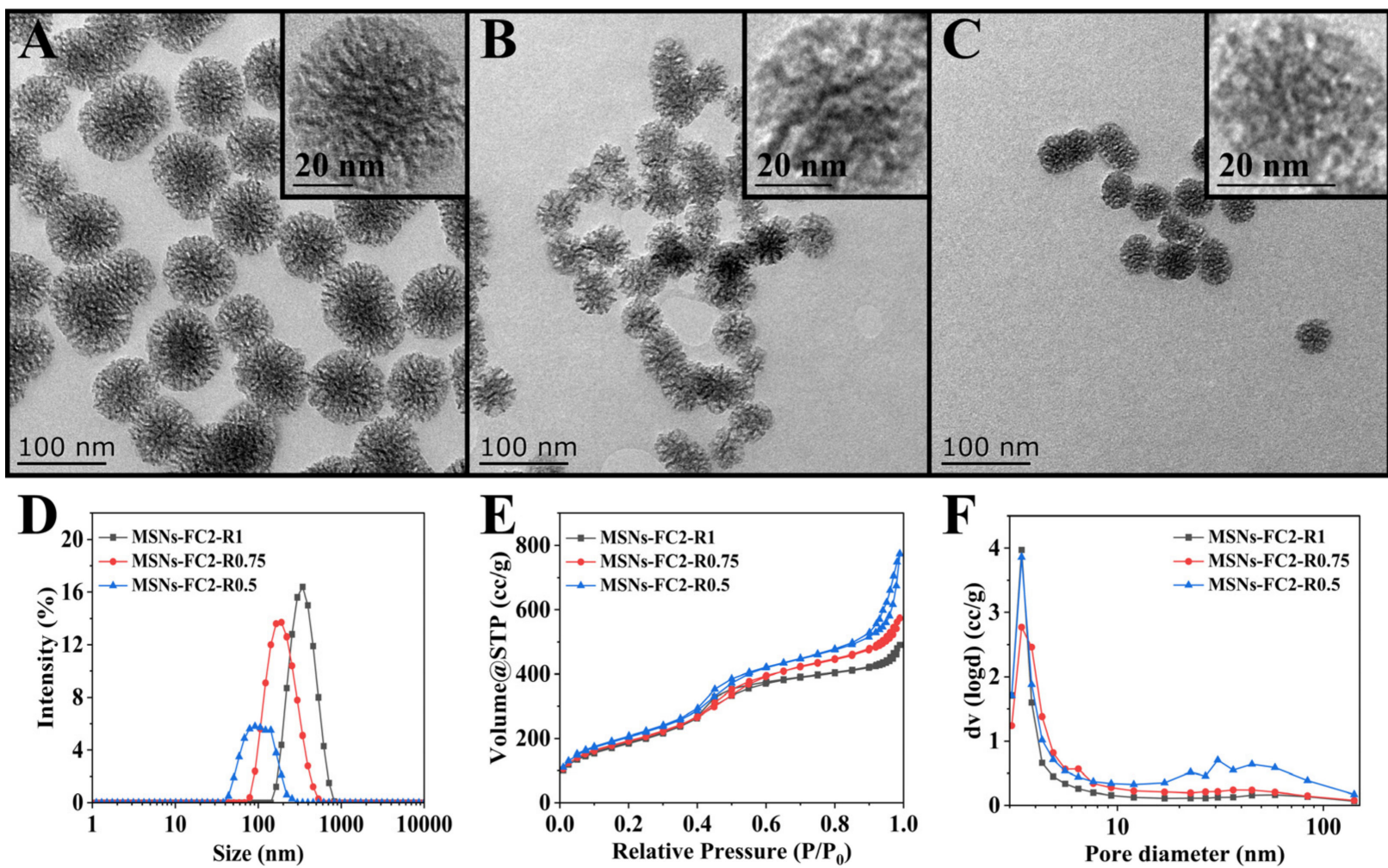

Figure 1. TEM images of (A) MSNs-FC2-R1, (B) MSNs-FC2-R0.75 and (C) MSNs-FC2-R0.5. (D) The particle size and (E) $\mathrm{N}_{2}$ adsorption-desorption curve and (F) the pore diameter of MSNs-FC2-R1, MSNs-FC2-R0.75, and MSNs-FC2-R0.5. 
To demonstrate the porous nature of MSNs, the $\mathrm{N}_{2}$ adsorption-desorption isotherms were performed at $77.3 \mathrm{~K}$, as shown in Figure 1E. The isotherms are identified as type IV according to The International Union of Pure and Applied Chemistry (IUPAC) classification [11], indicating a characteristic of mesoporous (2-50 nm) material [12]. The three MSNs samples demonstrated an increase in the adsorbed nitrogen volume at $\mathrm{P} / \mathrm{P}_{0}$ values around 0.4 and 0.9 , along with the emergence of $\mathrm{H} 1$ type hysteresis loop, suggesting the nitrogen capillary condensation inside the mesopores (Figure 1E). The Barrett-Joyner-Halenda (BJH) method [13] was used to determine the pore size distribution (PSD) of MSNs (Figure 1F). The surface area, pore size and pore volume of three MSNs were summarized in Table 1. When MSNs were synthesized using FC2 as an additive at various $R(R=1,0.75$ and $0.5)$, the specific BET surface area increased from 675.936 to $740.652 \mathrm{~m}^{2} \mathrm{~g}^{-1}$ and the pore volume increased from 0.7609 to $1.200 \mathrm{~cm}^{3} \mathrm{~g}^{-1}$, as $\mathrm{R}$ decreased. The pore diameter was of MSNs-FC2-R1, MSNs-FC2-R0.75, and MSNs-FC2-R0.5 was measured to be 4.503, 5.152, and $6.481 \mathrm{~nm}$, respectively.

Table 1. $\mathrm{N}_{2}$ adsorption-desorption data of MSNs.

\begin{tabular}{ccccc}
\hline Sample Name & $\mathbf{D}(\mathbf{n m})$ & $\mathbf{d}(\mathbf{n m})$ & $\mathbf{S}\left(\mathbf{m}^{\mathbf{2}} \mathbf{g}^{-\mathbf{1}}\right)$ & $\mathbf{V}\left(\mathbf{c m}^{\mathbf{3}} \mathbf{g}^{-\mathbf{1}}\right)$ \\
\hline R1 & 90 & 4.503 & 675.936 & 0.7609 \\
R0.75 & 50 & 5.152 & 691.091 & 0.8901 \\
R0.5 & 30 & 6.481 & 740.652 & 1.200 \\
\hline
\end{tabular}

Note: $\mathrm{D}$ is the particle size, $\mathrm{d}$ represents the pore size, $\mathrm{S}$ refers to the surface area, and $\mathrm{V}$ indicates the total pore volume.

In the synthesis system of FC2, $\mathrm{CTA}^{+}$cations and silicate species (from TEOS hydrolysis and condensation), fluorocarbon anions can counterpart the positively charged head groups of $\mathrm{CTA}^{+}$and insert into the hydrophobic part of micelles, leading to changes in hydrophobic conditions [14]. Herein, by adjusting the ratio of FC2 and CTAB, it is possible to change the structure of MSNs, and at a lower R, the surface area, pore size and pore volume of MSNs were generally higher [15].

\subsection{Tetracycline Loading and Release}

Fourier transform infrared spectroscopy (FT-IR) was performed to evaluate the loading of TCH on the MSNs. As shown in Figure 2A, pure MSNs showed a wide band at $1090 \mathrm{~cm}^{-1}$, and weak bands at $810 \mathrm{~cm}^{-1}$ and $465 \mathrm{~cm}^{-1}$, respectively, which were attributed to the asymmetric stretching vibration, symmetric stretching vibration and bending vibration of the Si-O-Si bond. The band at $970 \mathrm{~cm}^{-1}$ was attributed to the $\mathrm{Si}-\mathrm{OH}$ bending vibration. The bands at $3450 \mathrm{~cm}^{-1}$ and $1630 \mathrm{~cm}^{-1}$ were attributed to the asymmetric stretching vibration and the $\mathrm{H}-\mathrm{OH}$ bending vibration of water [16]. For pure $\mathrm{TCH}$, the band at $3450 \mathrm{~cm}^{-1}$ was due to the first overtone of $\mathrm{O}-\mathrm{H}$ bending, the peak at $1680 \mathrm{~cm}^{-1}$ corresponds to a $\mathrm{C}=\mathrm{O}$ vibration band [17]. In the case of $\mathrm{TCH}$-loaded MSNs, the band at $3450 \mathrm{~cm}^{-1}, 1090 \mathrm{~cm}^{-1}, 1630 \mathrm{~cm}^{-1}$ and $810 \mathrm{~cm}^{-1}$ were strongly reduced in intensity compared with MSNs. Moreover, the band at $1630 \mathrm{~cm}^{-1}$ was red-shifted by $120 \mathrm{~cm}^{-1}$ and the band at $3450 \mathrm{~cm}^{-1}$ was blue-shifted by $550 \mathrm{~cm}^{-1}$. This suggested that the new wrapped phase was formed between TCH and MSNs in the porous channels, changing the charge density [18]. The changes in the UV-Vis spectrum and the powder color of TCH-MSNs also demonstrated the successful load of TCH, as shown in Figure 2B.

The loading capacity of three types of MSNs was determined by measuring the OD value at $275 \mathrm{~nm}$ via UV-Vis spectrum. As shown in Figure 2C, MSNs-FC2-R1, exhibited the lowest loading capacity of $504.12 \mathrm{mg} / \mathrm{g}$, and MSNs-FC2-R0.5 showed the highest loading capacity of $548.81 \mathrm{mg} / \mathrm{g}$, which was attributed to the increased pore volume of MSNs-FC2R0.5. Figure S3 (Supplementary Materials) showed the surface zeta potential of MSNs before and after TCH loading in PBS solution. We noted that the surface charges of all three MSNs showed very small increases (1-2 mV) after TCH loading, indicating that most of the TCH molecule was immobilized in the mesopores of MSNs by non-covalent interactions instead of modifying on the surface of MSNs [19,20]. 

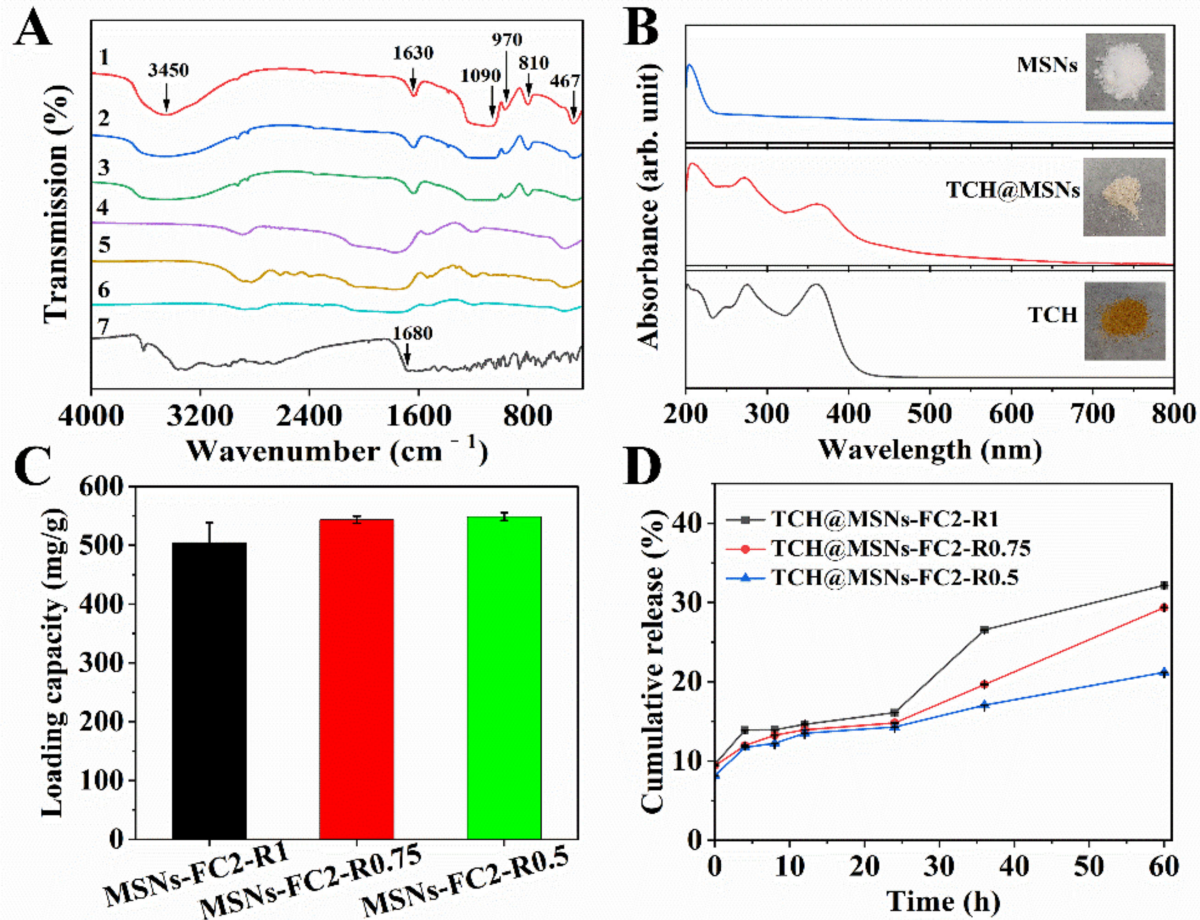

Figure 2. (A) FT-IR of (1) MSNs-FC2-R1, (2) MSNs-FC2-R0.75, (3) MSNs-FC2-R0.5, (4) TCH@MSNsFC2-R1, (5) TCH@MSNs-FC2-R0.75, (6) TCH@MSNs-FC2-R0.5 and (7) TCH. (B) UV spectra and digital photos (insert) of MSNs, TCH@MSNs and TCH. (C) The loading capacity of MSNs-FC2-R1, MSNs-FC2-R0.75 and MSNs-FC2-R0.5. (D) Cumulative release of TCH@MSNs-FC2-R1, TCH@MSNsFC2-R0.75 and TCH@MSNs-FC2-R0.5.

TCH release behavior from MSNs was examined under conditions with a fixed initial TCH concentration $(0.2 \mathrm{mg} / \mathrm{mL})$ in PBS. As shown in Figure 2D, three MSNs showed a more sustained release profile compared to the previous report [21]. The maximum cumulative release of MSNs-FC2-R1, MSNs-FC2-R0.75 and MSNs-FC2-R0.5 was 32.2\%, 29.4\% and $21.2 \%$, respectively, within $60 \mathrm{~h}$. Among them, MSNs-FC2-R0.5 showed the retarded release of TCH molecules especially after $24 \mathrm{~h}$, which may be related to the surface roughness and non-covalent interactions [15,22]. The drug delivery results demonstrated that the prepared three MSNs had large TCH adsorption capacities (over $500 \mathrm{mg} / \mathrm{g}$ ) and sustained drug releases over $60 \mathrm{~h}$, which could significantly maximize the long-term antibacterial efficacy of the drug.

\subsection{Antibacterial Activity of MSNs}

To assess the in vitro antibacterial activity of TCH-loaded MSNs, E. coli (ATCC25922) and TCH-resistant E. coli (MQ776) were selected as typical bacteria. TCH was chosen as the positive control group. The colony-forming units (CFUs) of bacteria after $24 \mathrm{~h}$ of incubation with TCH or TCH-loaded MSNs were investigated, respectively. As shown in Figure 3A,C, all groups exhibited dose-dependent antibacterial performance. We noted that more than half of the bacteria survived in the free TCH group even at the concentration of $4 \mu \mathrm{g} / \mathrm{mL}$ (Figure 3A). Meanwhile, TCH-loaded MSNs-FC2-R0.5 showed the lowest viability (from $9.01 \log$ to $2.19 \log$ ) at the same concentration compared with other groups, suggesting the strongest bactericidal activity, which was consistent with the photograph of the agar plate (Figure S4, Supplementary Materials). TCH-loaded MSNs-FC2-R0.5 had the lowest MIC value of $1 \mu \mathrm{g} / \mathrm{mL}$, which was lower than free TCH (MIC determined to be $2 \mu \mathrm{g} / \mathrm{mL}$ ), as shown in Table 2. The long-term antibacterial activity of TCH-loaded MSNs was evaluated by measurement of $\mathrm{OD}_{600}$ value. As shown in Figure 3B, TCH-loaded MSNs-FC2-R0.5 and MSNs-FC2-R0.75 at the concentration of $4 \mu \mathrm{g} / \mathrm{mL}$ exhibited maintained $100 \%$ inhibition 
towards E. coli throughout $72 \mathrm{~h}$. The long-term bacterial inhibition property should be attributed to the larger surface area and pore volume of MSNs, which enabled more TCH to enter inside the bacterial cells [23].
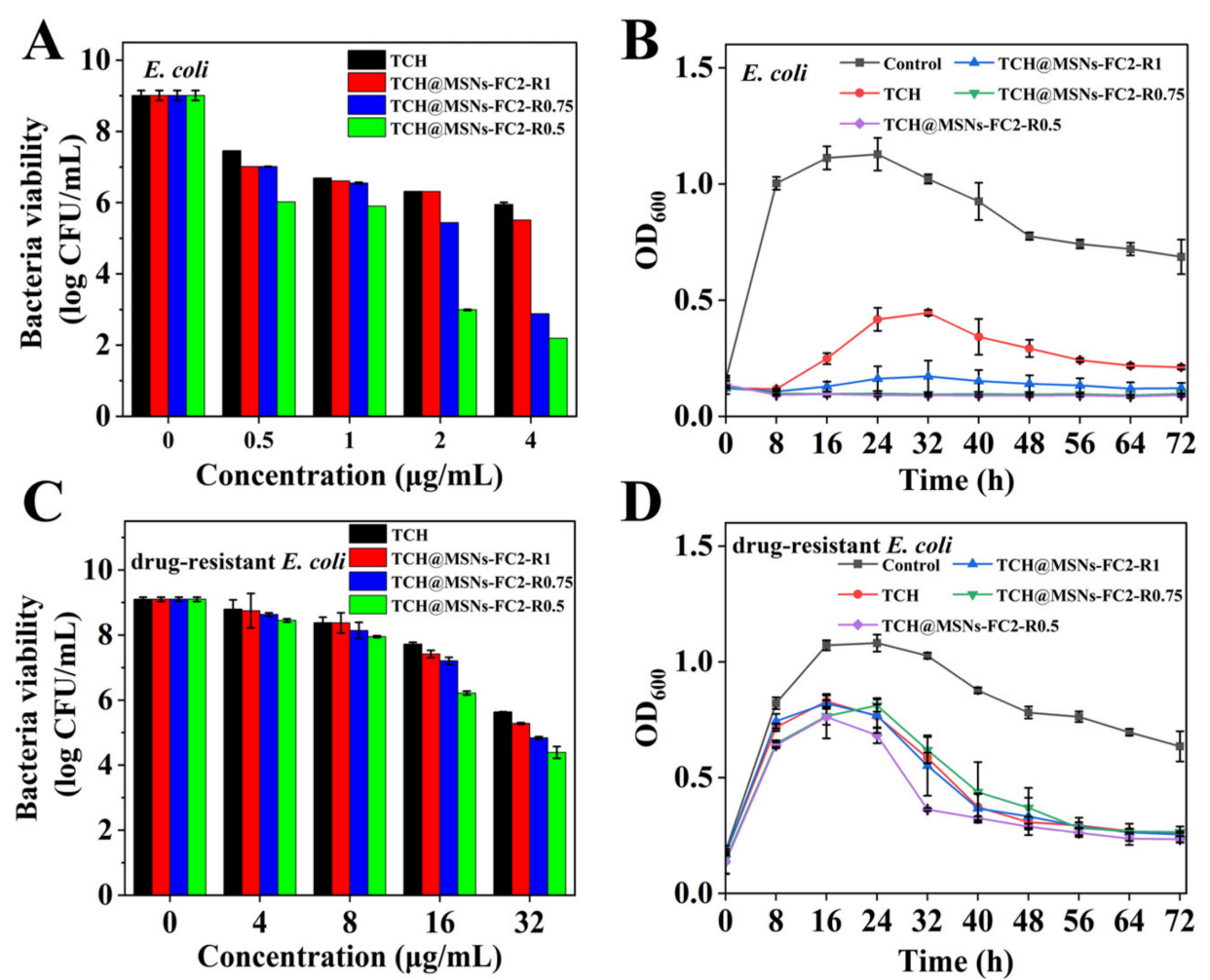

Figure 3. Bacteria viability of (A) E. coli and (C) drug-resistant E. coli incubated with TCH and MSNs loaded with TCH at different concentrations for $24 \mathrm{~h}$. Growth kinetics of (B) E. coli and (D) drugresistant $E$. coli incubated with TCH and MSNs loaded with TCH in $72 \mathrm{~h}$. The concentration of TCH in (B) and (D) was $4 \mu \mathrm{g} / \mathrm{mL}$ and $32 \mu \mathrm{g} / \mathrm{mL}$, respectively.

Table 2. Minimum inhibitory concentration (MIC).

\begin{tabular}{ccc}
\hline Sample name & Tetracycline Hydrochloride (TCH) & TCH@MSNs-FC2-R0.5 \\
\hline E. coli & $2 \mu \mathrm{g} / \mathrm{mL}$ & $1 \mu \mathrm{g} / \mathrm{mL}$ \\
(ATCC25922) & $32 \mu \mathrm{g} / \mathrm{mL}$ & $8 \mu \mathrm{g} / \mathrm{mL}$ \\
\hline
\end{tabular}

For drug-resistant E. coli, the antimicrobial activity of TCH-loaded MSNs was not as high as in E. coli. Even treated at the high concentration of $32 \mu \mathrm{g} / \mathrm{mL}$ for $24 \mathrm{~h}$, bacterial viability remains as high as $5.64 \mathrm{log}$ for TCH and $4.39 \mathrm{log}$ for TCH-loaded MSNs-FC2R0.5 (Figure 3C). The photograph of the agar plate confirmed the strongest inhibition of TCH-loaded MSNs-FC2-R0.5 towards drug-resistant E. coli compared with other groups (Figure S5 Supplementary Materials). The MIC value of TCH-loaded MSNs-FC2-R0.5 against TCH-resistant $E$. coli was $8 \mu \mathrm{g} / \mathrm{mL}$, which was 4 times lower than free TCH (MIC determined to be $32 \mu \mathrm{g} / \mathrm{mL}$ ), as shown in Table 2. Bacterial growth kinetics demonstrated that no differences in the inhibition of bacteria were observed after $40 \mathrm{~h}$ between $\mathrm{TCH}-$ loaded MSNs-FC2-R0.5 and TCH (Figure 3D). We speculated that at the beginning of inhibition (within $40 \mathrm{~h}$ ), more tetracycline was transported inside the bacteria, MSNs showed significant inhibition compared with free $\mathrm{TCH}$, but in the later period, more $\mathrm{TCH}$ molecules released from MSNs were discharged by the efflux pump in drug-resistant $E$. coli [24], which results in the decrease in the antibacterial activity of TCH-loaded MSNs against drug-resistant E. coli. 


\subsection{Antibacterial Mechanism}

To further investigate the effect of TCH-loaded MSNs on cellular structure, TEM was employed to observe the morphology changes in E. coli after treatment with TCH and TCH-loaded MSNs-FC2-R0.5 (at the concentration of $4 \mu \mathrm{g} / \mathrm{mL}$ ) for $24 \mathrm{~h}$ (Figure $4 \mathrm{~A}-\mathrm{C}$ ). In comparison with untreated cells (Figure 4A), both TCH and TCH-loaded MSNs treatments disrupted the E. coli cell membrane, resulting in the loss of integrity of the cell membrane and the leakage of cytoplasmic contents (Figure 4B,C). Especially, more severe membrane damage and cytoplasmic leakage were observed for bacteria treated with TCH-loaded MSNs-FC2-R0.5. Some bacteria appear hollow and disfigured cell walls, indicating the serious leakage of nucleic acids and proteins, which was consistent with the results shown in Figure 4D-G. Compared with the control and TCH groups, the bacteria after treatment with TCH-loaded MSNs-FC2-R0.5 for $6 \mathrm{~h}$ exhibited a higher amount of leaked nucleic acids and proteins.
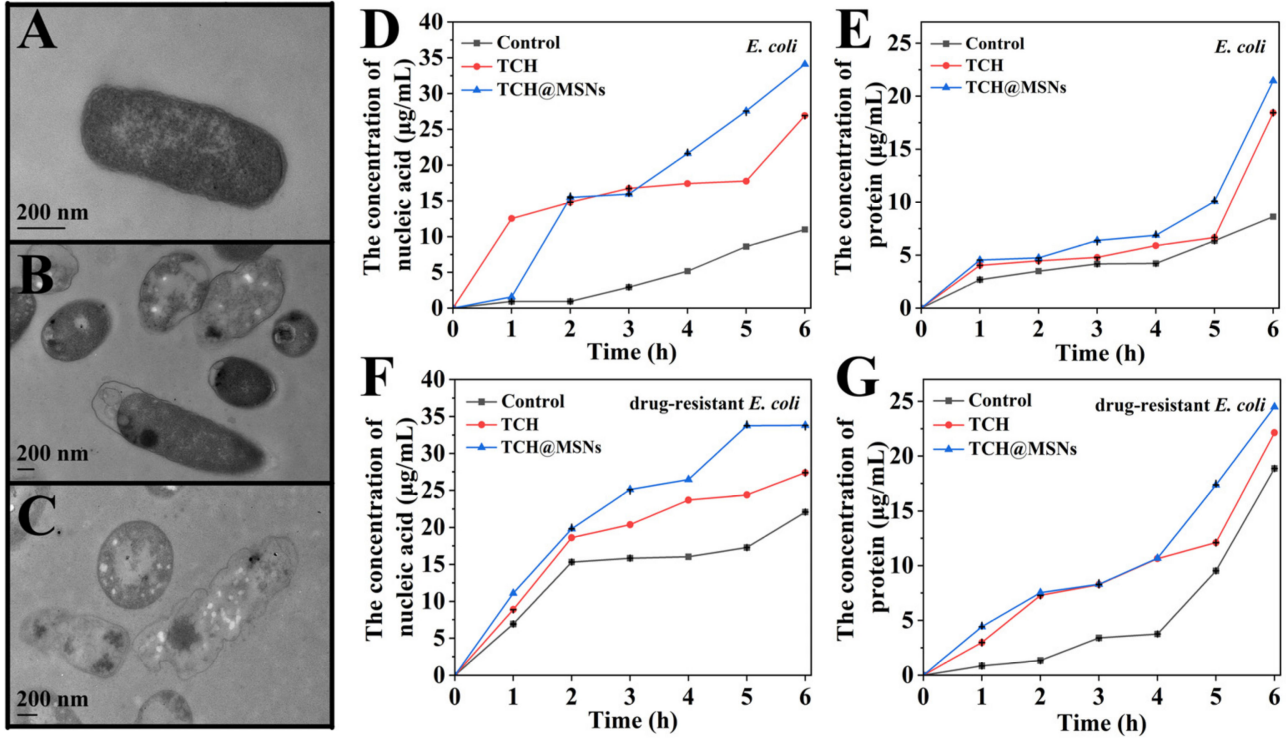

Figure 4. TEM images of E. coli after treatment with (A) PBS (control), (B) TCH and (C) TCH@MSNsFC2-R0.5 for $24 \mathrm{~h}$. The concentration of (D) nucleic acid and (E) protein released from E. coli after treatment with TCH@MSNs-FC2-R0.5 and TCH, respectively. The concentration of (F) nucleic acid and $(\mathbf{G})$ protein released from drug-resistant E. coli after treatment with TCH@MSNs-FC2-R0.5 and $\mathrm{TCH}$, respectively. The concentration of TCH in $(\mathbf{A}, \mathbf{D}, \mathbf{E})$ was $4 \mu \mathrm{g} / \mathrm{mL}$. The concentration of TCH in $(\mathbf{F}, \mathbf{G})$ was $32 \mu \mathrm{g} / \mathrm{mL}$.

The enhanced antibacterial activity of TCH-loaded MSNs-FC2-R0.5 was attributed to the efficient drug delivery of MSN and the inhibition of bacterial protein synthesis of TCH. High concentration TCH can be easily transported into the cells in a short time with the help of the MSN, they can bind to the receptor on the 30S subunit of the ribosome of bacteria, preventing the elongation of the peptide chain, and inhibiting the protein synthesis. The blocking of protein synthesis further changes the permeability of the bacterial cell membrane, resulting in cell death [25].

\section{Materials and Methods}

\subsection{Materials}

Cetyltrimethylammonium bromide (CTAB), triethanolamine (TEA), tetraethyl orthosilicate (TEOS, 98\%), sodium trifluoroacetate (FC2), tetracycline hydrochloride (TCH), were purchased from Sigma-Aldrich (Shanghai, China), phosphate buffer solution (PBS, $0.01 \mathrm{M}$, $\mathrm{pH}=7.2-7.4)$. 


\subsection{Preparation of Modified Mesoporous Silica Nanoparticles (MSNs)}

Mesoporous silica nanoparticles with adjustable pore size were prepared by tuning the molar ratios (R) of fluorocarbon anions to CTAB based on a previous report with some modifications [14]. Briefly, $380 \mathrm{mg}$ of CTAB and a certain amount of FC2 were added to $25 \mathrm{~mL}$ ultrapure water followed by adding $68 \mathrm{mg}$ of TEA, the mixture was stirred continuously for $1 \mathrm{~h}$ at $80^{\circ} \mathrm{C}$. Then, $1.5 \mathrm{~mL}$ of TEOS was added to the above-prepared mixture slowly and continuously. After the reaction was kept for $2 \mathrm{~h}$, the precipitate was collected by centrifugation at $5000 \mathrm{rpm}$ for $7 \mathrm{~min}$ (Allegra-64R Centrifuge, Beckman Coulter, CA, USA), and washed with ethanol several times. Then the precipitates were resolved in an ethanol solution of $\mathrm{NH}_{4} \mathrm{NO}_{3}(50 \mathrm{~mL}, 10 \mathrm{mg} / \mathrm{mL})$, and incubated at $60^{\circ} \mathrm{C}$ for $24 \mathrm{~h}$ to remove the surfactants [26]. The products were collected after centrifugation and denoted as MSNs-FC2-Rx, where $x$ represents the molar ratio of FC2 to CTAB.

\subsection{Tetracycline Hydrochloride Adsorption and Release Profile}

Typically, $2 \mathrm{mg}$ of MSNs were dispersed in $2 \mathrm{~mL}$ of $1 \mathrm{mg} / \mathrm{mL}$ TCH solution, the solution was stirred at room temperature for $12 \mathrm{~h}$. Unloaded TCH in the supernatant was collected by centrifugation at 13,000 rpm for $10 \mathrm{~min}$ and determined by using ultravioletvisible absorption spectrometry (UV-2600/2700, Shimadzu, Japan) at a wavelength of $275 \mathrm{~nm}$. A serial of TCH dilutions $(0.5-64 \mu \mathrm{g} / \mathrm{mL}$ ) was prepared in PBS as the standard curve (Figure S1, Supplementary Materials). The TCH loading capacity (mg/g) of MSNs can be calculated by the following formula:

$$
\text { Loading capacity }(m g / g)=\frac{T C H_{\text {total }}-T C H_{\text {supernatant }}}{m_{M S N s}}
$$

where $\mathrm{TCH}_{\text {total }}$ is the total content of $\mathrm{TCH}$ in solution, $\mathrm{TCH}_{\text {supernatant }}$ is the residual $\mathrm{TCH}$ content in the supernatant, $m_{M S N s}$ is the total content of MSNs in solution. In the blank control group, $2 \mathrm{~mL}$ of PBS $(0.01 \mathrm{M}, \mathrm{pH}=7.2-7.4)$ instead of TCH solution was mixed with $2 \mathrm{mg}$ of MSNs.

The release of TCH from the MSNs solution was investigated by a dialysis method. Briefly, $5 \mathrm{~mL}$ of TCH loaded MSNs solution was transferred into a dialysis bag $(\mathrm{MWCO}=14,000)$, which was further immersed in $100 \mathrm{~mL}$ of PBS solution $(0.01 \mathrm{M}$, $\mathrm{pH}=7.2-7.4$ ) with gentle shaking at $37^{\circ} \mathrm{C} .1 \mathrm{~mL}$ of the release medium (replacing with $1 \mathrm{~mL}$ of fresh PBS $(0.01 \mathrm{M}, \mathrm{pH}=7.2-7.4)$ was measured by using UV-Vis at a wavelength of $275 \mathrm{~nm}$. The drug cumulative release (\%) of MSNs was calculated by the following formula:

$$
\text { Cumulative release }(\%)=\frac{C n V+\sum_{i=1}^{n-1} C i V i}{m_{T C H}}
$$

where $\mathrm{Cn}$ is the TCH concentration in the sample at the nth sampling, $V$ is the total volume of released medium, $\mathrm{Ci}$ is the TCH concentration in the sample at the ith sampling, $\mathrm{Vi}$ is the sample volume at the ith sampling, and $m_{T C H}$ is the total quality of TCH in the input system.

\subsection{Characterization of MSNs}

The morphology of MSNs was observed by transmission electron microscopy (TEM, JEM-1011, JEOL, Tokyo, Japan) at $200 \mathrm{kV}$ (Cs $0.5 \mathrm{~mm}$, point resolution $1.9 \AA$ ). The size and zeta potential of MSNs were obtained with Zetasizer Nano ZS90 (Malvern Instruments Ltd., Malvern, UK). Nitrogen adsorption-desorption was measured by Quantachrome Instruments version 5.21 (Compass test Zhengzhou office, Zhengzhou, China) at $77 \mathrm{~K}$. The samples were degassed at $453 \mathrm{~K}$ overnight before the measurement. The total pore volume was calculated from the adsorbed amount at a relative pressure $\left(\mathrm{P} / \mathrm{P}_{0}\right)$ of 0.99 . The specific surface area was calculated based on Nitrogen adsorption-desorption measurements using Brunauer-Emmett-Teller (BET) method. The pore size distribution was calculated using Barrett-Joyner-Halenda (BJH) method. The structure information of MSNs before and 
after TCH loading was performed by Fourier transform infrared spectroscopy (FT-IR) (Nicolet-6700, Thermo Fisher Scientific, Shanghai, China). The spectra were obtained with $4 \mathrm{~cm}^{-1}$ resolution, and the average value was obtained in 64 scans.

\subsection{Antimicrobial Activity Assays}

\subsubsection{Bacterial Culture}

E. coli (ATCC25922) and tetracycline-resistant E. coli (MQ776) derived from soil samples [9] were cultured in Luria-Bertani (LB) broth at $37^{\circ} \mathrm{C}$ for $7 \mathrm{~h}$. The bacteria were harvested by centrifugation at $7000 \mathrm{rpm}$ for $7 \mathrm{~min}$, and the concentration was adjusted to approximately $10^{8}$ colony-forming units per milliliter $(\mathrm{CFU} / \mathrm{mL})$ by measuring the $\mathrm{OD}$ value at a wavelength of $600 \mathrm{~nm}$.

\subsubsection{Determination of Minimal Inhibitory Concentration (MIC)}

A total of $1 \mathrm{~mL}$ of the samples (TCH or TCH-loaded MSNs, including MSNs-FC2-R1, MSNs-FC2-R0.75, and MSNs-FC2-R0.5) in PBS at different TCH $(0.25-64 \mu \mathrm{g} / \mathrm{mL})$ concentrations were, respectively, added to $E$. coli and tetracycline-resistant $E$. coli suspension in sterile $\mathrm{LB}\left(1 \mathrm{~mL}\right.$ of $\left.10^{8} \mathrm{CFU} / \mathrm{mL}\right)$. The solution was incubated at $37^{\circ} \mathrm{C}$ for $24 \mathrm{~h}$. The turbidity of bacteria treated with TCH or TCH-loaded MSNs was determined by $\mathrm{OD}_{600}$ using a multifunctional microplate reader (Tecan infinite M200, Growth Curves Ltd., Raisio, Finland). Each concentration was prepared and measured in triplicate.

\subsubsection{Antibacterial Activity of MSNs In Vitro}

The total plate count method was used for testing the antibacterial activity of TCHloaded MSNs (MSNs-FC2-R1, MSNs-FC2-R0.75, and MSNs-FC2-R0.5) against E. coli and drug-resistant $E$. coli, respectively. Typical, bacterial suspension $\left(1 \mathrm{~mL}\right.$ of $\left.10^{8} \mathrm{CFU} / \mathrm{mL}\right)$ was added to $1 \mathrm{~mL}$ of TCH-loaded MSNs solution (MSNs-FC2-R1, MSNs-FC2-R0.75, and MSNs-FC2-R0.5). After $24 \mathrm{~h}$ of incubation at $37^{\circ} \mathrm{C}$, the solutions were collected, and the 10-fold serially diluted cells were spotted onto Baird-Parker and EMB agar. CFUs were counted after incubation at $37^{\circ} \mathrm{C}$ for $24 \mathrm{~h}$. Given that the sensitivity of common E. coli and drug-resistant $E$. coli to TCH was distinct, the concentration of TCH-loaded MSNs incubated with $E$. coli was $0.5,1,2$ and $4 \mu \mathrm{g} / \mathrm{mL}$, respectively, while the concentration of TCH-loaded MSNs incubated with drug-resistant E. coli was 4, 8, 16 and $32 \mu \mathrm{g} / \mathrm{mL}$, respectively. Meanwhile, TCH at the same concentration was used as the positive group, and saline $(0.9 \% \mathrm{NaCl})$ was used as the control group.

\subsubsection{Bacterial Kinetic Activity}

The bacterial kinetic activity after treatment with TCH or TCH-loaded MSNs was determined by $\mathrm{OD}_{600}$ reading within $72 \mathrm{~h}$. Typically, $1 \mathrm{~mL}$ of TCH or TCH-loaded MSNs (MSNs-FC2-R1, MSNs-FC2-R0.75, and MSNs-FC2-R0.5) in PBS was added to $1 \mathrm{~mL}$ of bacterial suspension in LB medium $\left(10^{8} \mathrm{CFU} / \mathrm{mL}\right)$, which was further incubated at $37^{\circ} \mathrm{C}$. aThe concentration of TCH-loaded MSNs incubated with E. coli was $4 \mu \mathrm{g} / \mathrm{mL}$, and the concentration of TCH-loaded MSNs incubated with drug-resistant E. coli was $32 \mu \mathrm{g} / \mathrm{mL}$. Each concentration was prepared and measured in triplicates.

\subsection{Determination of the Leaked Nucleic Acid and Proteins Content}

The concentration of nucleic acid leaked from E. coli and drug-resistant E. coli was determined by absorbance measurements at $260 \mathrm{~nm}\left(\mathrm{OD}_{260}\right)$. The bacterial suspension $\left(10^{8} \mathrm{CFU} / \mathrm{mL}\right)$ was incubated with TCH or TCH-loaded MSNs-FC2-R0.5 $(4 \mu \mathrm{g} / \mathrm{mL}$ and $32 \mu \mathrm{g} / \mathrm{mL}$ ), respectively, at $37^{\circ} \mathrm{C}$ for $6 \mathrm{~h}$. The supernatant was collected every $1 \mathrm{~h}$ by centrifugation at 13,000 rpm for $5 \mathrm{~min}$ and determined the absorbance value at $260 \mathrm{~nm}$. Saline was used as a control group.

The concentration of protein leaked from E. coli and drug-resistant E. coli was determined by following the Coomassie brilliant blue method. The bacterial suspension $\left(10^{8} \mathrm{CFU} / \mathrm{mL}\right)$ was incubated with TCH or TCH-loaded MSNs-FC2-R0.5 $(4 \mu \mathrm{g} / \mathrm{mL}$ and 
$32 \mu \mathrm{g} / \mathrm{mL}$ ), respectively, at $37^{\circ} \mathrm{C}$ for $6 \mathrm{~h}$. A total of $1 \mathrm{~mL}$ of the supernatant was collected every $1 \mathrm{~h}$ by centrifugation at 13,000 rpm for $5 \mathrm{~min}$ and added to $4 \mathrm{~mL}$ of staining solution. After incubation for $5 \mathrm{~min}$, the absorption was read at $595 \mathrm{~nm}$. The protein content was calculated by taking bovine serum protein as the standard curve (Figure S2, Supplementary Materials). Saline was used as a control group.

\section{Conclusions}

In summary, three types of MSN (MSNs-FC2-R1, MSNs-FC2-R0.75 and MSNs-FC2R0.5) with tunable particle diameter (30-90 nm) and pore size (4-6 nm) were fabricated by adjusting the amount of sodium trifluoroacetate (FC2). MSNs prepared in this work exhibited a high TCH loading capacity of up to $500-550 \mathrm{mg} / \mathrm{g}$ and a controlled release rate for long periods of $72 \mathrm{~h}$. Among them, MSNs-FC2-R0.5 with small particle size as well as larger pore size and volume showed the strongest antibacterial activity against E. coli and drug-resistant E. coli, after TCH loading. Moreover, the MIC value of TCHloaded MSNs-FC2-R0.5 was 4 times lower than that of TCH against drug-resistant E. coli, which may provide a new approach for the design of nanocarriers for the treatment of resistant bacteria.

Supplementary Materials: The following are available online, Figure S1. Standard curve of tetracycline hydrochloride, Figure S2. Standard curve of bovine serum albumin, Figure S3. Zeta potential of (a) MSNs-FC2-R1, (b) MSNs-FC2-R0.75, (c) MSNs-FC2-R0.5, (d) TCH, (e) TCH@MSNsFC2-R1, (f) TCH@MSNs-FC2-R0.75 and (g) TCH@MSNs-FC2-R0.5, Figure S4. Optical pictures of E. coli incubated with (A) Control, (B) TCH, (C) TCH@MSNs-FC2-R1, (D) TCH@MSNs-FC2-R0.75, (E) TCH@MSNs-FC2-R0.5 at the concentration of $4 \mu \mathrm{g} / \mathrm{mL}$, Figure S5. Optical pictures of drugresistant E. coli incubated with (A) Control, (B) TCH, (C) TCH@MSNs-FC2-R1, (D) TCH@MSNs-FC2R0.75, (E) TCH@MSNs-FC2-R0.5 at the concentration of $32 \mu \mathrm{g} / \mathrm{mL}$.

Author Contributions: Writing-original draft, Z.Y.; resources, S.W.; validation, Y.X.; supervision, J.Z.; project administration, W.Y. All authors have read and agreed to the published version of the manuscript.

Funding: This research was funded by the National Natural Science Foundation of China, grant number 32072318 and China Postdoctoral Science Foundation, grant number 2017T100375, 2016M600420.

Institutional Review Board Statement: Not applicable.

Informed Consent Statement: Not applicable.

Data Availability Statement: Not applicable.

Conflicts of Interest: The authors declare no conflict of interest.

Sample Availability: Samples of the compounds MSNs are available from the authors.

\section{References}

1. $\quad$ Bhattacharjya, S.; Straus, S.K. Design, Engineering and Discovery of Novel $\alpha$-Helical and $\beta$-Boomerang Antimicrobial Peptides against Drug Resistant Bacteria. Int. J. Mol. Sci. 2020, 21, 5773. [CrossRef] [PubMed]

2. Bragg, R.R.; Meyburgh, C.M.; Lee, J.Y.; Coetzee, M. Potential Treatment Options in a Post-antibiotic Era. In Infectious Diseases and Nanomedicine III; Springer: Singapore, 2018; Volume 1052, pp. 51-61.

3. Bernardos, A.; Piacenza, E.; Sancenon, F.; Hamidi, M.; Maleki, A.; Turner, R.J.; Martinez-Manez, R. Mesoporous Silica-Based Materials with Bactericidal Properties. Small 2019, 15, e1900669. [CrossRef]

4. Corvini, N.; El Idrissi, M.; Dimitriadou, E.; Corvini, P.F.; Shahgaldian, P. Hydrophobicity-responsive engineered mesoporous silica nanoparticles: Application in the delivery of essential nutrients to bacteria combating oil spills. Chem. Commun. 2019, 55, 7478-7481. [CrossRef] [PubMed]

5. Narayan, R.; Nayak, U.; Raichur, A.; Garg, S. Mesoporous Silica Nanoparticles: A Comprehensive Review on Synthesis and Recent Advances. Pharmaceutics 2018, 10, 118. [CrossRef] [PubMed]

6. Fernandez Marquez, M.L.; Grande Burgos, M.J.; Lopez Aguayo, M.C.; Pulido, R.P.; Galvez, A.; Lucas, R. Characterization of biocide-tolerant bacteria isolated from cheese and dairy small-medium enterprises. Food Microbiol. 2017, 62, 77-81. [CrossRef] [PubMed] 
7. Koneru, B.; Shi, Y.; Wang, Y.C.; Chavala, S.H.; Miller, M.L.; Holbert, B.; Conson, M.; Ni, A.; Di Pasqua, A.J. Tetracycline-Containing MCM-41 Mesoporous Silica Nanoparticles for the Treatment of Escherichia coli. Molecules 2015, 20, 19690-19698. [CrossRef]

8. Kankala, R.K.; Han, Y.H.; Na, J.; Lee, C.H.; Sun, Z.; Wang, S.B.; Kimura, T.; Ok, Y.S.; Yamauchi, Y.; Chen, A.Z.; et al. Nanoarchitectured Structure and Surface Biofunctionality of Mesoporous Silica Nanoparticles. Adv. Mater. 2020, 32, e1907035. [CrossRef] [PubMed]

9. Wang, S.; Gao, X.; Gao, Y.; Li, Y.; Cao, M.; Xi, Z.; Zhao, L.; Feng, Z. Tetracycline Resistance Genes Identified from Distinct Soil Environments in China by Functional Metagenomics. Front. Microbiol. 2017, 8, 1406. [CrossRef] [PubMed]

10. Nor, Y.A.; Zhang, H.; Purwajanti, S.; Song, H.; Meka, A.K.; Wang, Y.; Mitter, N.; Mahony, D.; Yu, C. Hollow mesoporous carbon nanocarriers for vancomycin delivery: Understanding the structure-release relationship for prolonged antibacterial performance. J. Mater. Chem. B 2016, 4, 7014-7021.

11. Sing, K.S.W. Reporting physisorption data for gas/solid systems with special reference to the determination of surface area and porosity (Recommendations 1984). Pure Appl. Chem. 1985, 57, 603-619. [CrossRef]

12. Shen, L.; Guo, L.; Chen, S.; Wei, A.; Osaka, A.; Chen, W. Self-assembly of silica spheres on silk fibroin spheres for synthesis of porous hollow silica spheres and their in vitro biocompatibility and drug delivery property. J. Non-Cryst. Solids 2019, 522, 119557. [CrossRef]

13. Shan, B.Q.; Xing, J.L.; Yang, T.Q.; Peng, B.; Hao, P.; Zong, Y.X.; Chen, X.Q.; Xue, Q.S.; Zhang, K.; Wu, P. One-pot co-condensation strategy for dendritic mesoporous organosilica nanospheres with fine size and morphology control. Crystengcomm 2019, 21, 4030-4035. [CrossRef]

14. Huo, Q.; Margolese, D.I.; Ciesla, U.; Feng, P.; Gier, T.E.; Sieger, P.; Leon, R.; Petroff, P.M.; Schüth, F.; Stucky, G.D. Generalized synthesis of periodic surfactant/inorganic composite materials. Nature 1994, 368, 137. [CrossRef]

15. Mishra, S.; Hook, J.M.; Nebhani, L. Priming the pores of mesoporous silica nanoparticles with an in-built RAFT agent for anchoring a thermally responsive polymer. Microporous Mesoporous Mater. 2019, 277, 60-69. [CrossRef]

16. Jiang, L.; Su, C.; Ye, S.; Wu, J.; Zhu, Z.; Wen, Y.; Zhang, R.; Shao, W. Synergistic antibacterial effect of tetracycline hydrochloride loaded functionalized graphene oxide nanostructures. Nanotechnology 2018, 29, 505102. [CrossRef] [PubMed]

17. Si, W.H.; Gao, Y.; Mei, X.; Wu, C.Q.; Li, J.G.; Zhang, J.H. Mesoporous silica nanoparticles loaded with capsaicin and their oxidation resistance in meat preservation. Food Chem. 2020, 344, 128737. [CrossRef] [PubMed]

18. Alavarse, A.C.; Castro, C.E.; Andrade, L.; Ferreira, F.F.; Bonvent, J.J. Synthesis of nanostructured mesoporous silica-coated magnetic nuclei with polyelectrolyte layers for tetracycline hydrochloride control release. Appl. Nanosci. 2020, 10, 3693-3702. [CrossRef]

19. Hashemikia, S.; Hemmatinejad, N.; Ahmadi, E.; Montazer, M. A novel cotton fabric with anti-bacterial and drug delivery properties using SBA-15- $\mathrm{NH}_{2}$ / polysiloxane hybrid containing tetracycline. Mater. Sci. Eng. C 2016, 59, 429-437. [CrossRef] [PubMed]

20. Haroosh, H.J.; Dong, Y.; Jasim, S.; Ramakrishna, S. Improvement of Drug Release and Compatibility between Hydrophilic Drugs and Hydrophobic Nanofibrous Composites. Materials 2021, 14, 5344. [CrossRef] [PubMed]

21. Florek, J.; Caillard, R.; Kleitz, F. Evaluation of mesoporous silica nanoparticles for oral drug delivery-current status and perspective of MSNs drug carriers. Nanoscale 2017, 9, 15252-15277. [CrossRef] [PubMed]

22. Li, C.; Hou, J.; Huang, Z.; Zhao, T.; Xiao, L.; Gao, G.; Harnoode, C.; Dong, A. Assessment of 2,2,6,6-tetramethyl-4-piperidinolbased amine $N$-halamine-labeled silica nanoparticles as potent antibiotics for deactivating bacteria. Colloids Surf. B Biointerfaces 2015, 126, 106-114. [CrossRef] [PubMed]

23. Saenger, W.; Orth, P.; Kisker, C.; Hillen, W.; Hinrichs, W. The Tetracycline Repressor-A Paradigm for a Biological Switch. Angew. Chem. Int. Ed. 2000, 39, 2042-2052. [CrossRef]

24. Bunick, C.G.; Keri, J.; Tanaka, S.K.; Furey, N.; Damiani, G.; Johnson, J.L.; Grada, A. Antibacterial Mechanisms and Efficacy of Sarecycline in Animal Models of Infection and Inflammation. Antibiotics 2021, 10, 439. [CrossRef] [PubMed]

25. Wang, Y.; Nor, Y.A.; Song, H.; Yang, Y.; Xu, C.; Yu, M.; Yu, C. Small-sized and large-pore dendritic mesoporous silica nanoparticles enhance antimicrobial enzyme delivery. J. Mater. Chem. B 2016, 4, 2646-2653. [CrossRef] [PubMed]

26. Heydari, S. Voltammetric mixture analysis of tyrosine and tryptophan using carbon paste electrode modified by newly synthesized mesoporous silica nanoparticles and clustering of variable-partial least square: Efficient strategy for template extraction in mesoporous silica nanoparticle synthesis. Sens. Actuators B Chem. 2017, 257, 1134-1142. 